Gut and Liver, Vol. 11, No. 6, November 2017, pp. 739-740

\title{
Does Proton Pump Inhibitor Increase the Clostridium difficile Infection Risk in the Treatment and Prophylaxis of Stress Ulcers than Histanime-2 Receptor Antagonist?
}

\author{
Chang Soo Eun \\ Department of Internal Medicine, Hanyang University Guri Hospital, Guri, Korea
}

See "Comparison of the Hospital-Acquired Clostridium difficile Infection Risk of Using Proton Pump Inhibitors versus Histamine-2 Receptor Antagonists for Prophylaxis and Treatment of Stress Ulcers: A Systematic Review and Meta-Analysis" by Mohamed Azab, et al. on page 781, Vol. 11. No. 6, 2017

Clostridium difficile infection (CDI), most common cause of hospital acquired infectious diarrhea, has been reported to be increasing in incidence, severity, and mortality over the past several decades throughout the world. Several risk factors for CDI have been demonstrated including antibiotics exposure, old age, prolonged hospital and intensive care unit (ICU) stay, previous CDI episode, co-morbidities, and acid suppression therapy such as proton pump inhibitors (PPIs), and histamine 2 receptor antagonists (H2RAs), and so forth. Among them, acid suppression therapy has recently received an increased attention as a risk factor for CDI. Several epidemiologic studies have suggested increased CDI risk is associated with both PPIs and H2RAs.

Meanwhile, PPIs and H2RAs have been commonly used for prophylaxis and treatment of stress ulcers in critically ill patients. Several randomized controlled trials (RCTs) and metaanalyses demonstrated that PPIs were more effective than H2RA in preventing gastrointestinal (GI) bleeding, while others reported no significant difference between PPIs and H2RAs. ${ }^{1}$ Furthermore, some meta-analyses revealed no mortality benefit in patients with stress ulcer prophylaxis (SUP) than those without SUP. ${ }^{2}$ Although critically ill patients are at high risk of developing stress related ulcerations, the prevalence of overt GI bleeding in these patients has been reported to be relatively low, around 5\%.

Several guidelines have recommended SUP just in patients with high risk factors for clinically important GI bleeding such as mechanical ventilation, coagulopathy, acute renal injury, and hepatic failure, and so forth. However, inappropriate use of gas- tric acid suppressants appear to be common in clinical practice. In some studies, 63\% of ICU patients and 60\% of hospitalized general ward patients, who prescribed SUP, had no appropriate indication and one-third of these patients were discharged without discontinuation of the medication.,

Several studies have demonstrated that both PPIs and H2RAs are associated with an increased risk of CDI occurrence. Although precise mechanisms of CDI occurrence by gastric acid suppression are not clear, loss of gastric acidic environment caused by PPIs or H2RAs has been suggested to induce bacterial overgrowth and altered distal gut microbiome with decreased bacterial diversity, which may contribute to CDI occurrence. The meta-analysis by Tleyjeh et al., ${ }^{5}$ which included 35 observational studies with a total of 201,834 participants, demonstrated a relative risk of 1.44 (95\% confidence interval, 1.22 to 1.70$)$ for CDI occurrence among patients with H2RA therapy. On the contrary, several meta-analyses have showed pooled odds ratios of 1.65 to 2.15 for CDI occurrence among patients with PPIs therapy. In addition, U.S. Food and Drug Administration recently warned CDI can be associated with PPIs use. ${ }^{6-8}$ However, it is unclear whether the relation of gastric acid suppression (PPIs and H2RAs) and CDI occurrence is causal or mere association, suggesting that future well-organized prospective RCTs would be warranted.

To date, there has been little data of meta-analyses directly comparing CDI occurrence risk between PPIs and H2RA among patients with stress ulcer treatment and prevention. In this issue of Gut and Liver, Azab et al. ${ }^{9}$ investigated the comparative

Correspondence to: Chang Soo Eun

Department of Internal Medicine, Hanyang University Guri Hospital, 153 Gyeongchun-ro, Guri 11923, Korea

Tel: +82-31-560-2228, Fax: +82-31-555-2998, E-mail: cseun@hanyang.ac.kr

pISSN 1976-2283 eISSN 2005-1212 https://doi.org/10.5009/gnl17430

@) This is an Open Access article distributed under the terms of the Creative Commons Attribution Non-Commercial License (http://creativecommons.org/licenses/by-nc/4.0) which permits unrestricted non-commercial use, distribution, and reproduction in any medium, provided the original work is properly cited. 
CDI risk of PPIs versus H2RAs in the prophylaxis and treatment of stress ulcers using a systematic review and meta-analysis. This meta-analysis, which included nine case-control and three cohort studies with a total of 74,132 patients, reported a pooled odds ratio of 1.386 (95\% confidence interval, 1.152 to 1.668 ; $\mathrm{p}=0.001$ ) for CDI occurrence among patients with PPIs use than those with H2RAs use. The results were consistent in the subgroup analyses of medication use purpose, study site, and study design. Therefore, current analysis suggest that PPIs use is associated with a higher risk of CDI occurrence by 38.6\% in the prevention and treatment of stress ulcers compared to H2RAs use. This study, a first meta-analysis directly compared CDI risk between PPI versus H2RA during prevention and treatment of stress ulcers so far, provide clinicians with a valuable insight into the SUP strategy in real practice.

However, the results of this study does not conclude that clinicians would be better to choose H2RAs for prophylaxis and treatment of stress ulcers than PPIs. As the authors described, the quality of evidence of individual studies enrolled in this meta-analysis was low, implying that conclusions of this study must be interpreted cautiously. In addition, this meta-analysis could not analyze the potential impact of antibiotics use, the most important risk factor on CDI occurrence, because of natural limitation of the study design. To validate current metaanalysis findings and apply to clinical practice, further largescaled prospective RCTs investigating the comparative efficacy of SUP, the potential influence on CDI occurrence, and the costeffectiveness between PPIs and H2RAs use, should be needed among patients with high risk of overt GI bleeding.

In summary, currently available clinical data suggest relatively weak evidence that PPIs use seem to be more effective in preventing clinically overt GI bleeding and more risky for CDI occurrence compared to H2RA use. At present, considering the increasing incidence and clinical impact of CDI, and widespread use of PPIs and those potential serious side effects, clinicians should try to be confident that benefits of PPIs use always outweigh the harms for individual patients. In addition, SUP with PPIs or H2RA should be limited to critically ill patients at high risk for clinically important GI bleeding.

\section{CONFLICTS OF INTEREST}

No potential conflict of interest relevant to this article was reported.

\section{REFERENCES}

1. Alhazzani W, Alenezi F, Jaeschke RZ, Moayyedi P, Cook DJ. Proton pump inhibitors versus histamine 2 receptor antagonists for stress ulcer prophylaxis in critically ill patients: a systematic review and meta-analysis. Crit Care Med 2013;41:693-705.

2. Krag M, Perner A, Wetterslev J, Wise MP, Hylander Møller M. Stress ulcer prophylaxis versus placebo or no prophylaxis in critically ill patients: a systematic review of randomised clinical trials with meta-analysis and trial sequential analysis. Intensive Care Med 2014;40:11-22.

3. Farley KJ, Barned KL, Crozier TM. Inappropriate continuation of stress ulcer prophylaxis beyond the intensive care setting. Crit Care Resusc 2013;15:147-151

4. Zink DA, Pohlman M, Barnes M, Cannon ME. Long-term use of acid suppression started inappropriately during hospitalization. Aliment Pharmacol Ther 2005;21:1203-1209.

5. Tleyjeh IM, Abdulhak AB, Riaz M, et al. The association between histamine 2 receptor antagonist use and Clostridium difficile infection: a systematic review and meta-analysis. PLoS One 2013;8:e56498.

6. Kwok CS, Arthur AK, Anibueze CI, Singh S, Cavallazzi R, Loke YK. Risk of Clostridium difficile infection with acid suppressing drugs and antibiotics: meta-analysis. Am J Gastroenterol 2012;107:1011-1019.

7. Janarthanan S, Ditah I, Adler DG, Ehrinpreis MN. Clostridium difficile-associated diarrhea and proton pump inhibitor therapy: a meta-analysis. Am J Gastroenterol 2012;107:1001-1010.

8. Deshpande A, Pant C, Pasupuleti V, et al. Association between proton pump inhibitor therapy and Clostridium difficile infection in a meta-analysis. Clin Gastroenterol Hepatol 2012;10:225-233.

9. Azab M, Doo L, Doo DH, et al. Comparison of the hospitalacquired Clostridium difficile infection risk of using proton pump inhibitors versus histamine-2 receptor antagonists for prophylaxis and treatment of stress ulcers: a systematic review and metaanalysis. Gut Liver 2017;11:781-788. 